\title{
A non-secretory malignant insulinoma: a case report
}

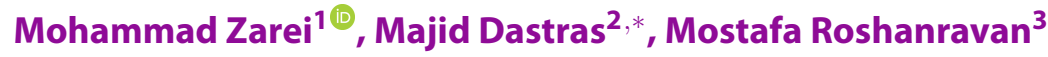

${ }^{1}$ Nursing Department, Shirvan Center of Higher Health Education, North Khorasan University of Medical Sciences, Bojnurd, Iran

${ }^{2}$ Nursing Department, Zahedan University of Medical Sciences, Zahedan, Iran

${ }^{3}$ Nursing Department, Faculty of Nursing and Midwifery, North Khorasan

University of Medical Sciences, Bojnurd, Iran

\section{Correspondence}

Majid Dastras, Nursing Department, Zahedan University of Medical Sciences, Zahedan, Iran

Email: dastrasm1@gmail.com

History

- Received: Nov 21, 2018

- Accepted: Mar 10, 2019

- Published: Mar 31, 2019

DOI :

https://doi.org/10.15419/bmrat.v6i3.533

\section{Check for updates}

\section{Copyright}

(c) Biomedpress. This is an openaccess article distributed under the terms of the Creative Commons Attribution 4.0 International license.

\begin{abstract}
Introduction: We report a rare case of non-insulin secreting malignant insulinoma of the pancreas and discuss its medical and surgical management. Case Presentation: Our patient was a 62year-old Persian female. Over the previous year, she had developed increased abdominal mass, dizziness, weakness, and fatigue. After surgical operation, chemotherapy was given to the patient. Treatment with cisplatin and etoposide was commenced in a 4-month course. Conclusion: As a result, chemotherapy showed an important role in the management of insulinoma.
\end{abstract}

Key words: Insulinoma, Malignant, Pancreas

\section{INTRODUCTION}

Pancreatic endocrine tumors (PETs), with mild to moderate malignancies, originate from pancreatic islets. The first case was detected in 1869 by Langerhans. These tumors are rare and the prevalence is 1-4 per million people ${ }^{1,2}$. Among all, insulinoma is the most common type and can be seen mostly in people between the ages of 30- to 60-year-old ${ }^{3,4}$.

Insulinoma accounts for only 1 percent of malignant pancreatic tumors and can occur with or without secretory function; and if it is combined with a hormonal syndrome, we considered it a secretory form $^{5}$. In non-secretory insulinoma, patients are asymptomatic until they develop gastric outlet obstruction or bile duct, or unless the tumor causes pain or are specified in imaging ${ }^{6}$.

\section{CASE PRESENTATION}

A 62-year-old Persian female, who showed symptoms of headache, dizziness, fatigue and muscle jump about two years ago, had admitted in a hospital with a diagnosis of meningiomas and was operated to remove the mass.

Over the previous year, she had developed increased abdominal mass, dizziness, weakness, and fatigue. This time, since the early studies on suspicion of insulinoma secretary, a fasting test was performed according to protocol. At first, the blood samples were collected to check for glucose, insulin and C-peptide levels of patient, and then fasting was given to patient under close supervision. It was recommended to measure the patient's blood sugar in a serial form according to protocol if the symptoms of hypoglycemia persisted. Due to the normality of the test results, an abdominal Computed Tomography (CT) scan was requested to complete the studies. The CT scan showed a pancreatic tumor sized $13 \times 8 \mathrm{~mm}$ along with extensive metastases to the surrounding area (Figure 1). For a definitive diagnosis, a needle biopsy and a pathologic examination were performed, and the malignant insulinoma diagnosis was confirmed. The dimension of the tumor was $6 \times 5.8 \times 13 \mathrm{~mm}$.

After surgical operation, chemotherapy was given to the patient. Treatment with cisplatin (I.V 170 $\mathrm{mg} /$ week) and etoposide (I.V $85 \mathrm{mg} /$ daily) was commenced in a 4-month course. The current state of patient is acceptable and stable. Currently, the patient is under constant monitoring and care.

\section{DISCUSSION AND CONCLUSIONS}

Endocrine tumors comprise a small percentage (1$2 \%$ ) of all pancreatic neoplasms. They are mostly seen in adults, but few cases have been reported in children and infants ${ }^{7}$. Overall it is a rare tumor (with a prevalence of 1 in 250 million) and the annual incidence is 1 to 5 per million ${ }^{8}$. $80 \%$ of cases were benign tumors and $40 \%$ of their size is below $1 \mathrm{~cm}^{9,10}$.

In a previous study, mean duration of symptoms before diagnosis was less than 1.5 years ${ }^{11}$. However, some patients may be asymptomatic for decades. Approximately $20 \%$ of patients are misdiagnosed with neurological or mental disorder before the diagnosis of insulinoma $^{12,13}$.

The results of non-invasive centralization techniques including ultrasonography, CT and magnetic resonance imaging (MRI) have been desponding, and sensitivities ranging from 0 to $33 \%$ have been reported ${ }^{14}$. In the present case, detection with CT Scan and final approval with needle biopsy was performed. 


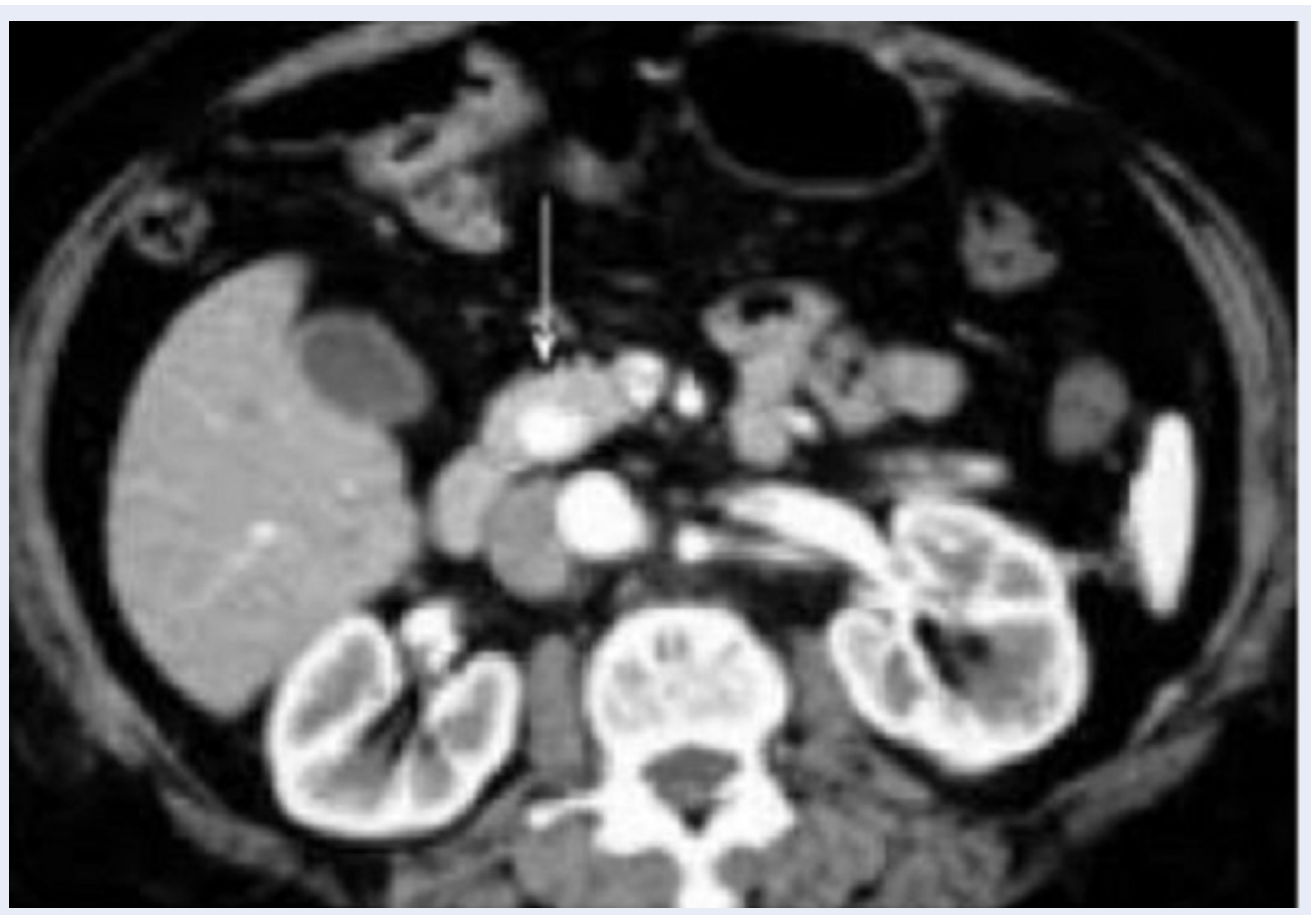

Figure 1: Pancreatic tumor sized $13 \times 8 \mathrm{~mm}$ along with extensive metastases to the surrounding area.

PET treatments include two-part problem solving: problems related to secreted hormones, and problems related to tumor growth and metastasis. Chemotherapy is one of the treatment methods that shows good result in patients ${ }^{15}$. In our case, according to the symptoms of abdominal pain and swelling, and no proof of secretory insulinoma, treatment with chemotherapy in the same regimen to small cell lung cancer based on CT Scan showed positive outcome. As a result, chemotherapy showed an important role in the management of insulinoma.

\section{ABBREVIATIONS}

CT: Computed tomography

PET: Pancreatic endocrine tumor

MRI: Magnetic resonance imaging

\section{COMPETING INTERESTS}

The authors report no conflicts of interest in this work.

\section{AUTHORS' CONTRIBUTIONS}

$\mathrm{MZ}$ and MD followed this case and drafted the manuscript; $\mathrm{MZ}$ and MR helped for the follow up of this case; $\mathrm{MZ}, \mathrm{MD}$, and MR revised this paper. All authors read and approved the final manuscript.

\section{ACKNOWLEDGMENTS}

The authors wish to acknowledge the following individuals for their contributions to this case report.

\section{REFERENCES}

1. Pandey D, Sharma B, Kumar S, Chauhan V, Gupta D, Sharma A. Insulinoma Presenting with Psychiatric Symptoms. Journal Indian Academy of Clinical Medicine. 2004;5(1):72-4.

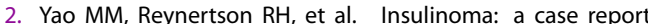
and review of the clinical features and diagnosis. Gundersen Lutheran Medical Journal. 2005;3:73-6.

3. Lever-Rosas CD, Enviquez-Pogan A, Chavaz-Rodrigue JJ, Galvan-Gonzalez JL, et al. Insulinoma- a case report. SevSanidMilitMex. 2001;55:170-3.

4. Mittendorf EA, Liu YC, McHenry CR. Giant insulinoma: case report and review of the literature. J Clin Endocrinol Metab. 2005;90(1):575-80. 15522939. Available from: 10.1210/jc. 2004-0825.

5. Halder PJ, Hafeezunnisa P, Pai R, Samsi AB. Insulinoma. J Postgrad Med. 1992;38(4):202-4. 1307597.

6. Dizon AM, Kowalyk S, Hoogwerf BJ. Neuroglycopenic and other symptoms in patients with insulinomas. Am J Med. 1999;106(3):307-10. 10190379. Available from: 10.1016/ S0002-9343(99)00021-2.

7. Juan R. Rosai and Ackerman's surgical pathology. New York: Mosby; 2004.

8. Solcia E, Capella C, Kloppel G. Tumors of the Pancreas. In: and others, editor. Atlas of tumor pathology. Washington DC: Armed forces institute of pathology; 1997. p. 120-130.

9. Schwartz S. Principles of surgery. Saunders Co.; 1999.

10. Correnti S. Intra operative ultrasonography for pancreatic Insulinoma. 43rd ed. and others, editor. Medline, Italy department of surgery; 1996.

11. Service FJ, McMahon MM, O'Brien PC, Ballard DJ. Functioning insulinoma, recurrence, and long-term survival of patients: a 60-year study. Mayo Clin Proc. 1991;66(7):711-9. 1677058. Available from: 10.1016/S0025-6196(12)62083-7. 
12. Service FJ, Dale AJ, Elveback LR, Jiang NS. Insulinoma: clinical and diagnostic features of 60 consecutive cases. Mayo Clin Proc. 1976;51(7):417-29. 180358.

13. Harrington MG, McGeorge AP, Ballantyne JP, Beastall G. A prospective survey for insulinomas in a neurology department. Lancet. 1983;1(8333):1094-5. 6133118. Available from: 10.1016/S0140-6736(83)91923-2.

14. Heerden JV. Pancreatic resection for carcinoma of the pan- creas: whipples versus total pancreatectomy - an institutional perspective. World J Surg. 1994;8(6). Available from: 10.1007/ BF01656028.

15. Wong LS, Hobbs S, Wright AD, Dorricott NJ. A non-insulin secreting malignant insulinoma of the pancreas. Eur J Surg Oncol. 2000;26(3):314-6. 10753540. Available from: 10.1053/ejso. 1999.0889 .

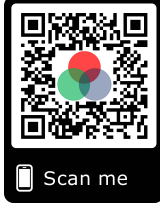

